\title{
Effect of a fire retardant on the ignition of pine wood exposed to smoldering particles of pine bark
}

\author{
Denis Kasymov ${ }^{l, *}$ and Alexander Paletsky ${ }^{2}$ \\ ${ }^{1}$ National Research Tomsk State University, 36 Lenin Ave., Tomsk, 634050, Russia \\ ${ }^{2}$ Institute of Chemical Kinetics and Combustion, Novosibirsk, 630090, Russia
}

\begin{abstract}
This paper represents the laboratory research results on the interaction of smoldering pine bark particles with pine wood. Fire retardant treatment "FUKAM" was studied to estimate its effect on the probability of wood ignition. The wind speed and the number and geometric sizes of particles were varied in the experiments. The results have shown that the increase in the wind speed leads to the increase in the probability of wood ignition by the particles of the same size, and fire-retardant treatment significantly increases the protective properties of wood exposed to smoldering pine bark particles.
\end{abstract}

\section{Introduction}

The main factors influencing on the ignition of construction materials and the propagation of fires in natural and urban areas are the radiative and convective heat transfer from fire, as well as the smoldering particles which can accumulate on the roof, in the corners of buildings, near fences or indoors, which may result in the ignition of buildings [1].

The works $[2,3]$ report that the production of smoldering particles is a process in which the combustible materials, such as shrubs, trees and building materials are heated and separated into smaller smoldering particles during a fire. After that the particles are transported from the fire by a convective column, initiate spot fires and cause the ignition of residential and industrial buildings.

One of the ways to reduce the flammability of synthetic and natural polymer materials (including wood) is the use of fire retardants which can be applied to a polymer, both throughout the volume during the production of materials and in the surface treatment of finished products.

Thus, the goal of this work is to study the ignition of preheated wood samples exposed to smoldering natural wood particles, as well as the effect of a fire-retardant coating on the fire hazard characteristics of wood.

\section{Experimental}

\footnotetext{
*Corresponding author: denkasymov@gmail.com
} 
The effect of the fire retardant coating was investigated using the "FUKAM" means [4].

To study the probable ignition of wood samples exposed to smoldering particles, the setup was modernized to carry out investigations concerning the ignition of fuel bed by smoldering particles [5]. The scheme of the setup is shown in Figure 1.

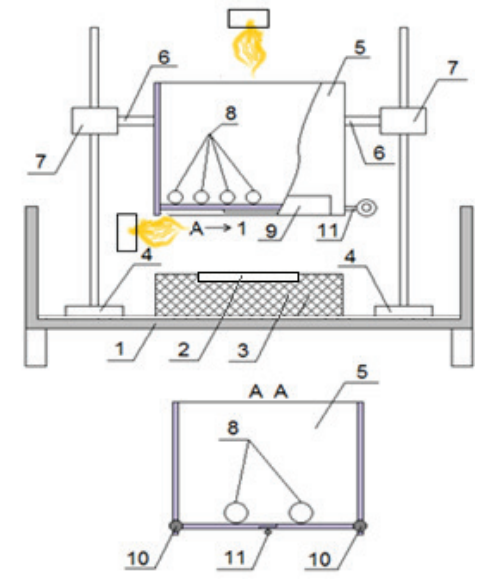

Fig. 1. Experimental setup: 1 is the - pan; 2 - wood sample; 3 - heat-insulating material; 4 - support; 5 - box; 6 - bracket; 7 - holder; 8 - particle samples; 9 - separated bottom; 10 - balls; 11 - stopper.

The imitators of smoldering particles were placed in the box (5) fixed to the supports (4) and having the holes in the bottom for the uniform heating of particles, excluding the probability of particle loss during the experiments. The particles were ignited and started smoldering using two gas burners (Energy GT-1-100). The gas flow rate of the burner was $80 \mathrm{~g} /$ hour. The composition of the gaseous mixture was as follows: $9 \%$ of propane, $25 \%$ of butane, $60 \%$ of isobutane, and $6 \%$ of impurities. For uniform heating the one burner was placed under the box (5) and the other one was over it. Before conducting the experiment, the wood sample was heated up to a temperature of $200 \div 220{ }^{\circ} \mathrm{C}$ for 4 minutes [6, 7]. It allowed the conditions to be modeled when the wooden building was exposed to the heat flow from the forest fire front $[8,9]$. After that, the substrate with the sample was moved under the box with the particles which were preheated by the gas burners and then thrown down.

The standard solid pine board with the size of $(0.23 \times 0.095 \times 0.022) \mathrm{m}^{3}$ was used as the sample in the experiments. The size measurement accuracy was $\pm 0.002 \mathrm{~m}^{3}$. The samples were insulated from the environment by an insulating material in such a way that only the largest part of the surface $\left(\mathrm{S}=218.5 \mathrm{~cm}^{2}\right.$ ) remained open. Figure 2 shows the photographs of wood before the experiment, as well as the heating element.

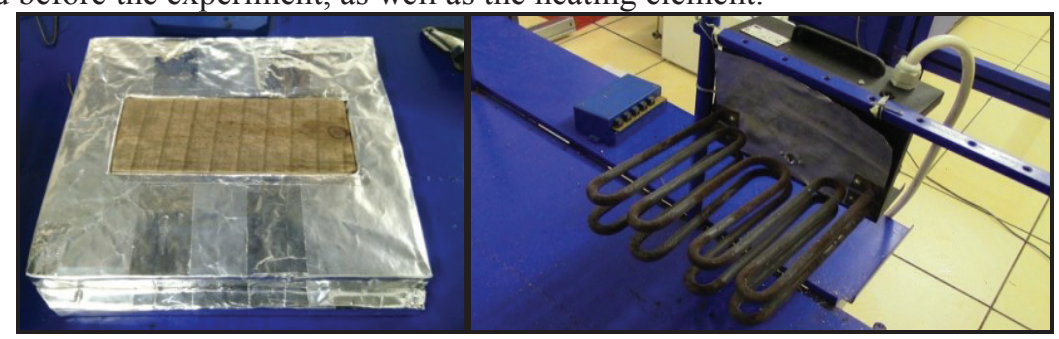

Fig. 2. Wood prepared for the experiment (left) and the heating element (right). 
The dipping treatment of the sample was used as a method to add a fire retardant solution to the wood sample. The wood samples were in the liquid solution "FUKAM" for 3 hours, so that the wood was completely covered with liquid. Then the samples were placed in a force-draft oven FDO-0.5 - 200 with a temperature of $70^{\circ} \mathrm{C}$ until complete drying. Consumption of the means "FUKAM" corresponds to the ASTM E119-00a [10] that provides the II group of fire retardant resistance.

Fresh-gathered pine bark with the characteristic linear sizes $\mathrm{L}=(10,15 ; 20,25,30) \cdot 10^{-3}$ $\mathrm{m}$ and a thickness $\mathrm{h}=(4 \div 5) \cdot 10^{-3} \mathrm{~m}$ was used as the imitators of smoldering particles in all experiments. The particle size was chosen based on the data obtained during the field experiments [1].

In a series of experiments a one smoldering particle was first used, then two particles and so on up to 10 particles to model the ignition of wood beginning from one particle and finishing with "fire rain". Three repetitions were performed for each experiment. The wood sample was considered to be ignited if the ignition occurred at least in one of the three experiments.

The weight of the wood samples was $290 \mathrm{~g}$, the wood density was $520 \mathrm{~kg} / \mathrm{m}^{3}$. The initial moisture content of the wood samples was $7.8 \%$ and that of the pine bark particles was $2.9 \%$.

The exposure time of the burners was determined depending on the particle size and was: 12 seconds for the particles with a size $\mathrm{L}=(10,15 ; 20) \cdot 10^{-3} \mathrm{~m}$ and 15 seconds for the particles with a size $\mathrm{L}=(25,30) \cdot 10^{-3} \mathrm{~m}$. According to the data obtained earlier [11], the minimum temperature of smoldering pine bark was $190{ }^{\circ} \mathrm{C}$.

Since in real conditions the exposure of smoldering particles to fuel bed and different wooden buildings is accompanied by a number of natural factors, in particular, by the heated air flow from the front of forest fire, so for this reason in the experiments the smoldering particles which were thrown down on the test wood samples were blown with a flow of heated air supplied by a drying fan with a rate and a temperature of 1, 1.5, 2, 2.5 $\mathrm{m} / \mathrm{s}$ and $40,50,60,110{ }^{\circ} \mathrm{C}$, respectively. A further increase in the flow rate led to the entrainment of particles outside the site. The rate of the flow directed perpendicular to the falling smoldering particles was determined using an anemometer CFM Master 8901 with a measurement error of $2 \%$. The air flow was directed to the surface of the wood sample in the area of throwing the particles by using a nozzle.

\section{Results}

Figure 3 shows the comparison of the experimental results to estimate the ignition of the preheated pine wood surface depending on the size and number of the smoldering particles interacting with the surface at various air flow rates. In the graphs, the areas I and II represent the values at which the wood sample ignition is possible (I) or not (II).

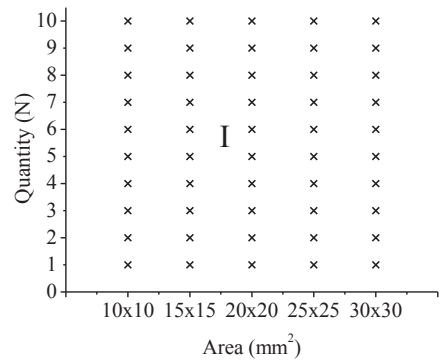

(a)

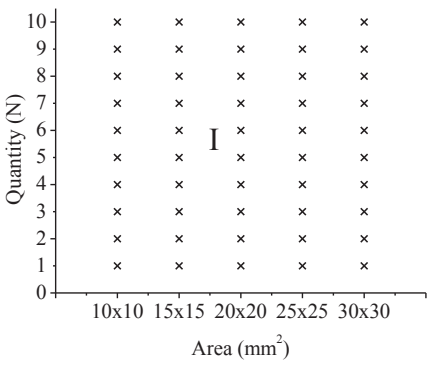

Area $\left(\mathrm{mm}^{2}\right)$ 

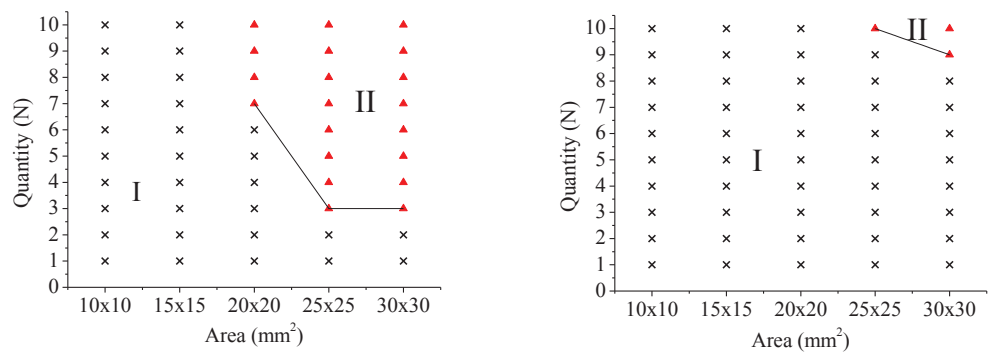

(b)
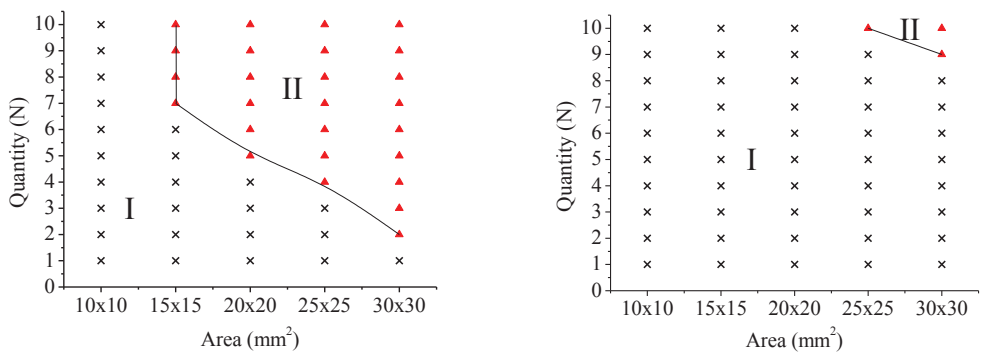

(c)
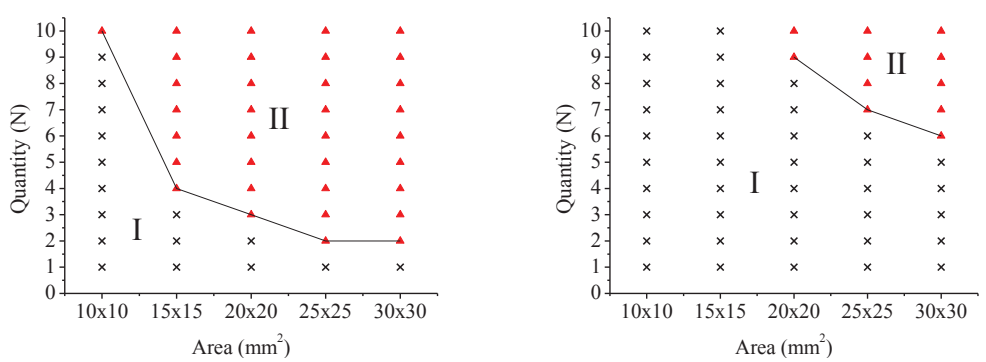

(d)

Fig. 3. Ignition of preheated pine wood with fire retardant treatment (right) and without (left) at different wind speeds (a) $1 \mathrm{~m} / \mathrm{s}, \mathrm{T}=40{ }^{\circ} \mathrm{C}$; (b) $1.5 \mathrm{~m} / \mathrm{s}, \mathrm{T}=50^{\circ} \mathrm{C}$; (c) $2 \mathrm{~m} / \mathrm{s}, \mathrm{T}=60^{\circ} \mathrm{C}$; (d) $2.5 \mathrm{~m} / \mathrm{s}, \mathrm{T}=110{ }^{\circ} \mathrm{C}$.

Figure 3 demonstrates that ignition is not observed for all sizes of particles (Fig. 3a) at a wind speed of $1 \mathrm{~m} / \mathrm{s}$, both for the untreated wood and the wood with fire retardant treatment. For the speed $\mathrm{V}=1.5 \mathrm{~m} / \mathrm{s}$, there is a region II in which the wood is ignited. The surface was found to be ignited by the particles, the geometric dimensions of which exceeded $20 \cdot 10^{-3} \mathrm{~m}$ for the untreated wood and $25 \cdot 10^{-3}$ for the treated one. In addition, as is seen from the graph, the increase in the size of the particles leads to the decrease in their number.

The analysis of the graphs shows that the increase in the wind speed results in the increase in the probability of the ignition by the particles of the same size for the wood that is not treated with a flame retardant. For example, increasing the wind speed from 1.5 to 2.5 $\mathrm{m} / \mathrm{s}$ leads to the fact that the minimum number of the particles with a size $\mathrm{L}=(20,30) \cdot 10^{-3}$ $\mathrm{m}$, sufficient to ignite the wood, decreases from 7 and 3 , up to 3 and 2, respectively. The number of particles also influences on the wood ignition process. The minimum total area of smoldering particles, which is equal to the product of the particle number, sufficient for 
ignition, by the characteristic area, significantly increases when the wood is treated with a fire retardant. The average value of this quantity calculated for the different characteristic sizes of particles at a speed of $1.5 \mathrm{~m} / \mathrm{s}$ is $24 \pm 5 \mathrm{~cm}^{2}$ for the untreated wood and $72 \pm 9 \mathrm{~cm}^{2}$ for the wood treated with "FUKAM", respectively. This value is inversely proportional to the wind speed. In addition, the surface occupied by the smoldering particles during ignition was about $11 \%$ for the untreated wood and $~ 33 \%$ for the wood treated with "FUKAM".

The observations have shown that the wood treated with a fire retardant is ignited when the particles dropped on it start the flaming combustion due to the air flow, and then the combustion spreads to the wood.

Analyzing the results on the exposure of the smoldering pine bark particles to the wood treated with a fire retardant, it is noted that only in a few cases the prolonged exposure of flame caused by the particles blown by the air flow at the speeds of $1.5 \div 2.5 \mathrm{~m} / \mathrm{s}$ leads to the ignition of wood.

Figure 4 shows a typical picture that demonstrates the exposure of smoldering particles to the wood treated with a fire retardant ( 5 particles with a size of $30 \cdot 10^{-3} \mathrm{~m}$ at a wind speed of $2.5 \mathrm{~m} / \mathrm{s})$.

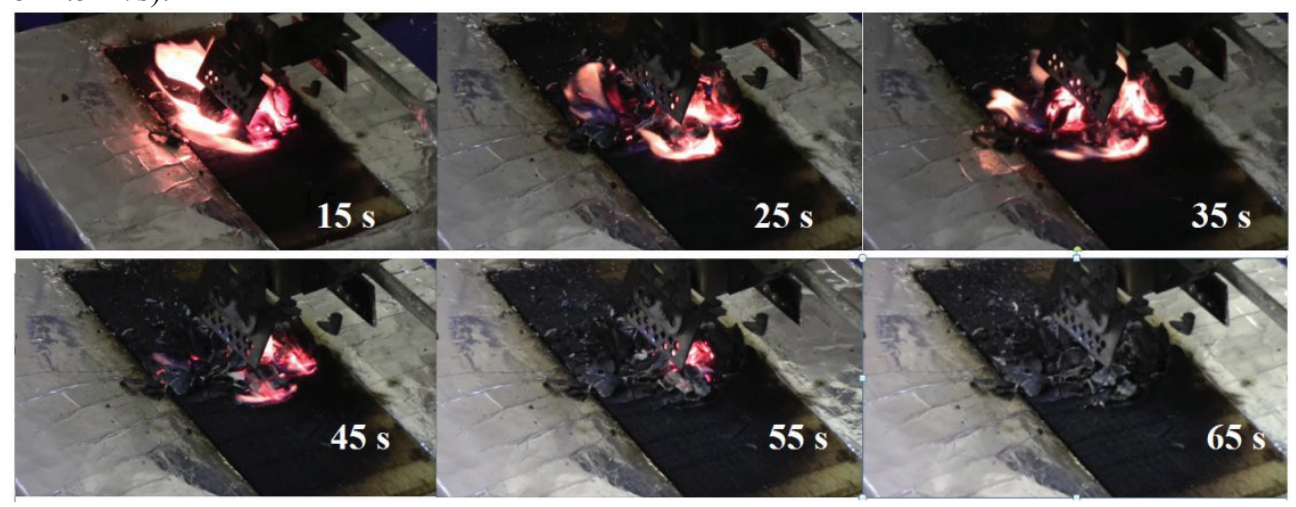

Fig.4. Exposure of smoldering particles to the wood sample treated with a fire retardant (5 particles with a size of $30 \cdot 10^{-3} \mathrm{~m}$ were used at a wind speed of $2.5 \mathrm{~m} / \mathrm{s}$ ).

It is seen that the large inflow of oxidizer into the combustion zone results in the flaming particle combustion that lasts about 1 minute. However, this does not lead to the ignition of wood, but there is local charring in the contact area of particles with the wood sample, which is likely to be connected to the inhibitory properties of a fire retardant.

\section{Conclusion}

For the chosen parameters of the experiment the pine wood samples treated with the means "FUKAM" were resistant to the exposure of smoldering pine bark particles (up to 10 smoldering particle with a size of $25 \cdot 10^{-3} \mathrm{~m}$ ) and a wind speed (up to $2 \mathrm{~m} / \mathrm{s}$ ). The empirical value was determined within the frameworks of the conditions chosen to conduct the experiment and was equal to the total area of smoldering pine bark particles, normalized to the wind speed sufficient to initiate the ignition $(1.5 \mathrm{~m} / \mathrm{s})$, namely $24 \pm 5 \mathrm{~cm}^{2}$ for the preheated pine wood and $72 \pm 9 \mathrm{~cm}^{2}$ for the board treated with a fire retardant "FUKAM". The results of the experiments show that the effect of fire retardant treatment "FUKAM" significantly increases the protective properties of wood exposed to smoldering pine bark particles. 
This study was supported by the Russian Foundation for Basic Research (project No. 16-33-50133).

\section{References}

1. M. El Houssami, E. Mueller, A. Filkov, J. C. Thomas, N. Skowronski, M. R. Gallagher, K. Clark, R. Kremens, A. Simeoni, Fire Technol. 52, 731 (2015).

2. S. L. Manzello, S. Suzuki, Y. Hayashi, Fire Saf, J. 52, 181 (2012).

3. A. C. Fernandez-Pello, C. Lautenberger, D. Rich, C. Zak, J. Urban, R. Hadden, S. Scott, S. Fereres, Combust. Sci. Technol. 187, 269 (2015)

4. The special substance for processing different fabrics and building materials "FUKAM": http://www.fukam.ru/English.

5. A. Filkov, D. Kasymov, V. Zima, O. Matvienko, AIP Conf. Proc. 1698, 060004 (2016).

6. R. M. Aseeva, B. B. Serkov, A. B. Sivenkov, Gorenie drevesiny i ee pozharoopasnye svojstva, (EMERCOM of Russia, Moscow, 2010).

7. V. Babrauskas, Fire Saf. J. 40, 528 (2005).

8. J. D. Cohen, J. Forest. 98, 15 (2000).

9. R. G. Rehm, A. Hamins, H. R. Baum NISTIR, 6891 (2001).

10. ASTM E119-00a, Fire Tests of Building Construction and Materials, (2004).

11. A. Filkov, S. Prohanov, E. Mueller, D. Kasymov, P. Martynov, M. El Houssami, Jan Thomas, N. Skowronski, B. Butler, M. Gallagher, K. Clark, W. Mell, R. Kremens, R. M. Hadden, A. Simeoni, Proc. Combust. Inst. (to be published). 